\title{
Effects of Short-Term Soil Tillage Management on Activity and Community Structure of Denitrifiers under Double- Cropping Rice Field
}

\author{
Haiming Tang ${ }^{1 *}$, Chao Li ${ }^{1}$, Kaikai Cheng ${ }^{1}$, Lihong Shi', Li Wen ${ }^{1}$, Xiaoping Xiao ${ }^{1}$, Yilan $\mathrm{Xu}^{2}$, \\ Weiyan $\mathrm{Li}^{1}$, and Ke Wang ${ }^{1}$ \\ ${ }^{1}$ Hunan Soil and Fertilizer Institute, Changsha 410125, P.R. China \\ ${ }^{2}$ Hunan Biological and Electromechanical Polytechnic, Changsha 410127, P.R. China
}

Soil physical and chemical characteristics, soil potential denitrification rates (PDR), community composition and nirK-, nirS- and nosZ-encoding denitrifiers were studied by using MiSeq sequencing, quantitative polymerase chain reaction (qPCR), and terminal restriction fragment polymorphism (T-RFLP) technologies base on short-term (5-year) tillage field experiment. The experiment included four tillage treatments: conventional tillage with crop residue incorporation (CT), rotary tillage with crop residue incorporation (RT), no-tillage with crop residue retention (NT), and rotary tillage with crop residue removed as control (RTO). The results indicated that soil organic carbon, total nitrogen and $\mathrm{NH}_{4}{ }^{+}-\mathrm{N}$ contents were increased with $\mathrm{CT}, \mathrm{RT}$ and $\mathrm{NT}$ treatments. Compared with RTO treatment, the copies number of nirK, nirS and nos $Z$ in paddy soil with CT, RT and NT treatments were significantly increased. The principal coordinate analysis indicated that tillage management and crop residue returning management were the most and the second important factors for the change of denitrifying bacteria community, respectively. Meanwhile, this study indicated that activity and community composition of denitrifiers with CT, RT and NT treatments were increased, compared with RTO treatment. This result showed that nirK, nirS and nosZ-type denitrifiers communities in crop residue applied soil had higher species diversity compared with crop residue removed soil, and denitrifying bacteria community composition were dominated by Gammaproteobacteria, Deltaproteobacteria, and Betaproteobacteria. Therefore, it is a beneficial practice to increase soil PDR level, abundance and community composition of nitrogen-functional soil microorganism by combined application of tillage with crop residue management.

Keywords: Tillage, crop residue, paddy field, soil denitrification rate, community composition

Received: July 10, 2020 Accepted: September 21, 2020

First published online: September 22, 2020

*Corresponding author Phone: +86-731-84696102 Fax: +86-731-84691581 E-mail : tanghaiming66@163.com

pISSN 1017-7825 eISSN 1738-8872

Copyright(C) 2020 by The Korean Society for Microbiology and Biotechnology

\section{Introduction}

Denitrification is an important microbial process in the nitrogen $(\mathrm{N})$ cycling of farmland ecosystem, and it was a facultative respiratory process in which oxidized $\mathrm{N}$ compounds are used as alternative electron acceptors for energy production when oxygen is limited [1]. The process includes a sequence of reactions that reduce nitrate $\left(\mathrm{NO}_{3}^{-}\right)$to dinitrogen $\left(\mathrm{N}_{2}\right)$, passing first through nitrite $\left(\mathrm{NO}_{2}^{-}\right)$, nitric oxide $(\mathrm{NO})$, and nitrous oxide $\left(\mathrm{N}_{2} \mathrm{O}\right)$ [2]. Previous study has been proved that denitrification is the main process of $\mathrm{N}$ transformation in paddy soil [3]. Bacterial nitrite reductase (NiR) was playing an important role in reducing of $\mathrm{NO}_{2}^{-}$to $\mathrm{NO}$ in denitrifying organisms $[2,4]$. The functional genes nirK and nirS encode nitrate reductase. Other studies showed a close relationship between the abundance of nirK and nirS and the $\mathrm{N}_{2} \mathrm{O}$ emission $[5,6]$. Meanwhile, the reduction of $\mathrm{N}_{2} \mathrm{O}$ to $\mathrm{N}_{2}$ were mainly catalyzed by nitrous oxide reductase (nos $\mathrm{Z}$ ) [7].

It is widely accepted that soil structure, soil organic carbon (SOC), soil moisture and temperature were affected by different types of tillage and crop residue practices, which modify the soil quantity and fertility [8]. Result of previous studies, these results indicated that denitrifier activity and community structure of denitrifier were playing a vital role in regulating $\mathrm{N}$ emission from farmland soil $[5,6]$ and are in tuen regulated by different tillage practices [9]. The abundance of nirK and nirS genes was shown to increase with no-tillage (NT) practice, while the abundance of nos $Z$ gene were decreased with conservation tillage (CT) practice [10]. Tatti et al. (2015) [11] also demonstrated that abundance of nirK and nosZ genes in paddy soil were increased with NT treatment, compared with CT treatment. Yu et al. (2018) [12] result found that Magnetospirillum and Rhodocyclaceae were accounted for the main component of denitrifiers in black soil. Therefore, the abundance of nirK, nirS and nosZ genes are 
often investigated to assess the $\mathrm{N}$-cycle microbial activity and diversity in soil $[3,13,14]$. At the same time, soil potential denitrification rates (PDR) are usually regarded as an explaining factor controlling denitrification in the soil under different rotation cropping system, fertilizer regime, tillage and so on [7, 10, 14]. However, there is still needed on the effects of combined application of tillage with crop residue management on activity and diversity of denitrifier and nitrifier in paddy soil.

Rice (Oryza sativa L.) is a major grain crops around the world, and the early rice and late rice rotation system (double-cropping rice system) is also the main planting system in southern China [15], where paddy soil fertility and quality are mostly affected by combined applied tillage (rotary tillage, conventional tillage, and no-tillage) with crop residue management. The different short-term combined applied tillage with crop residue practice has had obvious effects on soil physicochemical properties such as soil pH, soil bulk density, and SOC content, which were in return affects soil microbiological characteristics and yield of rice yield [16]. Further study is needed to determine the effects of different tillage treatments on the activities and communities of denitrifiers in doublecropping rice paddy soil under continuous 5 -year tillage with crop residue condition. We hypothesized that soil properties (i.e., soil pH, SOC, $\mathrm{NH}_{4}{ }^{+}-\mathrm{N}$, and $\mathrm{NO}_{3}{ }^{-} \mathrm{N}$ contents, and availability of $\mathrm{C}$ and $\mathrm{N}$ contents) were increased by application of tillage with crop residue management which also change the activities and diversity of denitrifiers in paddy soil were also changed. Therefore, the abundances and community structure of denitrifiers in paddy soil were studied by using MiSeq sequencing, quantitative polymerase chain reaction (qPCR) and terminal restriction fragment polymorphism (T-RFLP) technologies, respectively. Hence, the objective of this study was: (1) to investigate the response of soil chemical properties response to different tillage management; and, (2) to evaluate the activity and community structure of denitrifiers (nirK, nirS, and nosZ) under different tillage management in double-cropping rice paddy soil of southern China.

\section{Materials and Methods \\ Sites and Cropping System}

The field experiment was begun in November 2015. It was located in Ningxiang County $\left(28^{\circ} 07^{\prime} \mathrm{N}, 112^{\circ} 18^{\prime} \mathrm{E}\right)$ of Hunan Province, China. The annual mean precipitation, annual mean evapotranspiration, and monthly mean temperature of the experiment region, as well as soil texture and soil type, crop rotation system, soil physicochemical characteristics at tillage layer $(0-20 \mathrm{~cm})$ of the paddy field prior to this experiment were as described as by Tang et al. (2019) [16].

\section{Experimental Design}

The experiment were included four tillage treatments: conventional tillage with crop residue incorporation (CT), rotary tillage with crop residue incorporation (RT), no-tillage with crop residue retention (NT), and rotary tillage with all crop residue removed as control (RTO). The area of the each plots were $56.0 \mathrm{~m}^{2}(7 \mathrm{~m} \times 8 \mathrm{~m})$, and each tillage treatments was laid out in a randomized complete block design with three replications. The total quantity of Chinese milk vetch and rice straw returned to paddy fields, $C$ content of crop residue (Chinese milk vetch, early rice and late rice straw), depth of tillage, cultivars of early rice and late rice, fertilizer, and herbicide and irrigation management with different tillage treatments of paddy fields were as described as by Tang et al. (2019) [16].

\section{Soil Sampling}

Soil samples at tillage layer (0-20 cm depth) were collected in August 2019, at the tillering stage of late rice. Soil samples were collected by randomly from six cores from each plots, and rice roots were removed from soil samples and then passed through a $2-\mathrm{mm}$ mesh sieve. The fresh soil samples were placed immediately in an ice box and transported to the laboratory where they stored at $-20^{\circ} \mathrm{C}$ until molecular analysis in the laboratory.

\section{Soil laboratory Analysis}

Chemical analysis. Soil chemical properties were measured according to the methods described as by Bao (2000) [17]. Briefly, soil pH was measured with a compound electrode (PE-10, Germany) by using a soil to water ratio of 1:2.5. Soil organic carbon (SOC) and total nitrogen (TN) concentrations were measured by using a mass spectrometer elemental analyzer (Carlo Erba 1110, CE Instruments). Soil ammonium N $\left(\mathrm{NH}_{4}{ }^{+} \mathrm{N}\right.$ ) and nitrate $\mathrm{N}$ $\left(\mathrm{NO}_{3}{ }^{-} \mathrm{N}\right)$ concentrations were measured by using a flow injection autoanalyzer (FLA star 5000 Analyzer, Foss, Denmark).

Soil potential denitrification rates (PDR) and potential $\mathrm{N}_{2} \mathrm{O}$ emission. The $\mathrm{N}_{2}$ and $\mathrm{N}_{2} \mathrm{O}$ concentrations of soil samples were analyzed by using a robotized sampling and analyzing system, which were analyzed according to the methods described as by Molstad et al. (2007) [18]. Briefly, the soil samples were measured by using a gas chromatograph (GC, Agilent 7890), and the GC conditions for analyzed $\mathrm{N}_{2} \mathrm{O}$ and $\mathrm{N}_{2}$ concentrations were equipped with electron capture detector at $330^{\circ} \mathrm{C}$. Finally, the soil $\mathrm{N}_{2} \mathrm{O}$ and $\mathrm{N}_{2}$ emission rates were analyzed by using slope of linear regression between the change in concentrations of $\mathrm{N}_{2} \mathrm{O}$ and $\mathrm{N}_{2}$ versus time. Soil PDR of each tillage treatment were investigated according to the methods described as by Drury et al. (2007) [19]. Briefly, soil samples were placed in Erlenmeyer flask, and distilled water, glucose and nitrate were added into flask for investigate soil PDR.

DNA extraction, qPCR, and clone library analysis of N-related functional genes. Soil DNA extraction, qPCR, and clone library analysis of N-related functional genes were measured according to the methods described as by Throbäck et al. (2004) [20]. Briefly, soil DNA was extracted from $0.5 \mathrm{~g}$ (wet weight) samples by using the Fast DNA SPIN Kit (for soil, Bio 101, USA) according to manufacturer's instructions. The concentration of extracted DNA were measured by determining absorbance at 260 and $280 \mathrm{~nm}$ on a Nano Drop $2000 \mathrm{UV}$-Vis 
Spectrophotometer (Thermo Scientific). The DNA quality was examined by $1 \%$ agarose gel electrophoresis.

The primers were used to determine the abundance of nirK, nirS, and nirK, and the thermal cycling conditions were described as by Throbäck et al. (2004) [20]. Purified PCR amplicons were digested with different restriction endonuclease assemblies (for nirK, Sau96I [G'GNCC] and HpyCH4V [TG'CA]; for nirS and nosZ, BccI [CCATC $(\mathrm{N})^{\prime}{ }_{4}$ ] and BsaHI [GR'CGYC]). All terminal restriction fragments (TRFs) $<50 \mathrm{bp}$ and $<5 \%$ of the total peak height were excluded to avoid potential noise before counting relative TRF abundances. N-related microbial community was investigated by using the number of peaks and the heights of the peaks.

qPCR reaction mixtures contained $10 \mu \mathrm{l}$ of GoTaq qPCR Master Mix (Promega), $200 \mu \mathrm{M}$ of each primer, $2 \mu \mathrm{l}$ of tenfold diluted DNA template (10-20 ng), and ultraclean water to $20 \mu \mathrm{l}$ total volume. In this study, these primers used for qPCR were the same as in a conventional PCR. Addition of bovine serum albumin and ten-fold dilution were used to decrease the inhibitory effects of coextracted substances in soil DNA samples. Plasmid DNAs of the $\mathrm{N}$-related respective functional genes were extracted from soil samples DNA and serially diluted to generate a standard curve, these detailed data on standard curve, qPCR efficiency and cycling condition were as described as by Long et al. (2012) [21].

Illumina MiSeq sequencing. The soil denitrifying bacterial communities were analyzed according to the methods described as by Jung et al. (2011) [22]. Briefly, PCR amplification was conducted by using a Gene Amp PCR-System 9700 in a total volume of $20 \mu \mathrm{l}$ containing dNTPs $(2 \mu \mathrm{l}), 5 \times$ FastPfu Buffer $(4 \mu \mathrm{l})$, FastPfu Polymerase $(0.4 \mu \mathrm{l})$, primer $(0.8 \mu \mathrm{l})$, and template DNA $(10 \mathrm{ng})$. Amplicons were extracted from $2 \%$ agarose gels and purified by using the AxyPrep DNA Gel Extraction Kit (Axygen Biosciences, USA). The purified amplicons were pooled in an equimolar ratio and paired-end sequenced $(2 \times 250)$ on an Illumina MiSeq platform according to the standard protocols. The operational taxonomic units (OTU) were clustered with a $97 \%$ similarity cut off by using UPARSE (version $7.1 \mathrm{http}: / /$ drive5.com/uparse/), and an OTU table was generated for each sample for statistical analysis. The response ratio were used to determine changes in bacterial relative abundance compared to a control with a 95\% confidence interval [23]. Phylotypes were identified by using the Ribosomal Database Project (RDP) pyrosequencing pipeline (http://rdp.cme.msu.edu/). Thresholds for OTU clustering were chosen based on existing literature: $80 \%$ for $n o s Z, 82 \%$ for $n i r S$, and $83 \%$ for nirK. Raw FASTA files were quality-filtered by using QIIME software (version 1.17) with the previous criteria, and chimeric sequences were removed by using the UCHIME algorithm, The detailed information on raw FASTA files and chimeric sequences was as described as by Jung et al. (2011) [22].

The diversity of nirK, nirS and nosZ-containing communities were calculated according to the equation:

Shannon index $=-\sum(n i / \mathrm{N}) \times \ln (n i / \mathrm{N})$

where, $n i$ was the relative abundance of the ithT-RF, $i$ was the numbering of each T-RF in the T-RFLP spectrum, and $N$ was the total sum of relative abundances of selected T-RF for all samples in the T-RFLP spectrum.

The pattern of similarity in soil microbial community composition between different tillage treatments was indicated by using principal coordinate analysis (PCoA).

\section{Statistical Analysis}

The results of each investigated items were presented as average value and standard error. The statistical analysis of relative data was conducted by using the SAS 9.3 software package [24]. In addition, all investigated items with different treatments in this manuscript were compared by using one-way analysis of variance (ANOVA) following standard procedures at the $p<0.05$ probability level. The relationship between the soil properties and the abundances of denitrifying bacterial communities were analyzed by using the Pearson correlation test.

\section{Results}

\section{Soil Chemical Properties}

The results showed that soil $\mathrm{pH}$ were increased with CT, RT and NT treatments, compared with RTO treatment. However, there were no significantly differences $(p>0.05)$ in soil pH between CT, RT, NT and RTO treatments (Table 1). SOC and TN contents with RT treatment were higher $(p<0.05)$ than that of RTO treatment. Compared with RTO treatment, soil $\mathrm{NH}_{4}{ }^{+}-\mathrm{N}$ content with CT, RT and NT treatments was significantly increased $(p<0.05)$, and soil $\mathrm{NO}_{3}^{-}-\mathrm{N}$ content with RT and NT treatments was also significantly increased $(p<0.05)$, respectively.

Table 1. Soil pH and nutrient contents with different tillage treatments at tillering stage of late rice.

\begin{tabular}{lcccc}
\hline \multicolumn{1}{c}{ Treatments } & $\mathrm{CT}$ & $\mathrm{RT}$ & $\mathrm{NT}$ & $\mathrm{RTO}$ \\
\hline $\mathrm{pH}$ & $5.82 \pm 0.17 \mathrm{a}$ & $5.84 \pm 0.16 \mathrm{a}$ & $5.81 \pm 0.16 \mathrm{a}$ & $5.78 \pm 0.15 \mathrm{a}$ \\
$\mathrm{TN}\left(\mathrm{g} \mathrm{kg}^{-1}\right)$ & $2.17 \pm 0.06 \mathrm{ab}$ & $2.20 \pm 0.06 \mathrm{a}$ & $2.12 \pm 0.05 \mathrm{ab}$ & $2.08 \pm 0.05 \mathrm{~b}$ \\
$\mathrm{SOC}\left(\mathrm{g} \mathrm{kg}^{-1}\right)$ & $22.88 \pm 0.66 \mathrm{a}$ & $22.45 \pm 0.64 \mathrm{a}$ & $21.14 \pm 0.61 \mathrm{ab}$ & $20.35 \pm 0.58 \mathrm{~b}$ \\
$\mathrm{NH}_{4}^{+}-\mathrm{N}\left(\mathrm{mg} \mathrm{kg}^{-1}\right)$ & $0.14 \pm 0.01 \mathrm{c}$ & $0.16 \pm 0.01 \mathrm{~b}$ & $0.19 \pm 0.01 \mathrm{a}$ & $0.11 \pm 0.01 \mathrm{~d}$ \\
$\mathrm{NO}_{3}^{-} \mathrm{N}\left(\mathrm{mg} \mathrm{kg}^{-1}\right)$ & $0.12 \pm 0.01 \mathrm{c}$ & $0.14 \pm 0.01 \mathrm{~b}$ & $0.16 \pm 0.01 \mathrm{a}$ & $0.11 \pm 0.01 \mathrm{c}$ \\
\hline
\end{tabular}

CT: conventional tillage with crop residue incorporation; RT: rotary tillage with crop residue incorporation; NT: no-tillage with crop residue retention; RTO: rotary tillage with crop residue removed as control. TN: total nitrogen; SOC: soil organic carbon. Different lowercase letters in the same line were indicated significantly difference at $p<0.05$.

The same as below. 
A

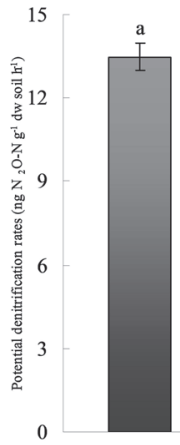

CT

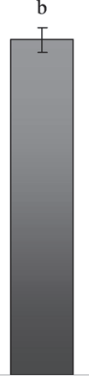

RT

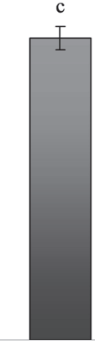

NT

Soil tillage treatments

B

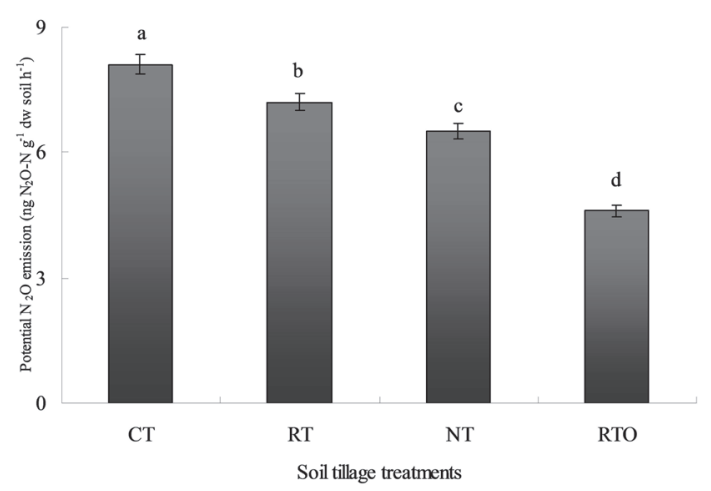

Fig. 1. Potential denitrification rates and potential $\mathrm{N}_{2} \mathrm{O}$ emission in paddy soil under different tillage treatments. (A) Potential denitrification rates; (B) Potential $\mathrm{N}_{2} \mathrm{O}$ emission. CT: conventional tillage with crop residue incorporation; RT: rotary tillage with crop residue incorporation; NT: no-tillage with crop residue retention; RTO: rotary tillage with crop residue removed as control. Vertical bars represent the standard deviation $(n=3)$ and different lowercase letters indicated significantly differences among tillage treatments in paddy soil at $p<0.05$. The same as below.

\section{Soil Potential Denitrification Rates and Potential $\mathrm{N}_{2} \mathrm{O}$ Emission}

The results indicated that soil potential denitrification rates (PDR) were profound affected by different tillage treatments (Fig. 1A). The soil PDR with different tillage treatments were ranged from 8.65 to $13.46 \mathrm{ng} \mathrm{N}_{2} \mathrm{O}-\mathrm{N} \mathrm{g}^{-1}$ $\mathrm{dw}$ soil $\mathrm{h}^{-1}$, and the soil PDR with CT, RT and NT treatments were higher $(p<0.05)$ than that of RTO treatment. The PDR was the highest with CT treatment and the lowest with RTO treatment in paddy soil (13.46 and $8.65 \mathrm{ng}$ $\mathrm{N}_{2} \mathrm{O}-\mathrm{N} \mathrm{g}^{-1} \mathrm{dw}$ soil h${ }^{-1}$, respectively). Additionally, compared with RTO treatment, the PDR in paddy soil were 25.43\%-55.61\% higher with CT, RT and NT treatments. Although the soil PDR were also increased with RT and NT treatments, the decrease of ranged from $10.48 \%$ to $19.39 \%$ with RT and NT treatments compared with CT treatment (Fig. 1A).

The potential $\mathrm{N}_{2} \mathrm{O}$ emission with different tillage treatments were ranged from 4.6 to $8.1 \mathrm{ng} \mathrm{N} \mathrm{O}_{2}-\mathrm{N} \mathrm{g}^{-1} \mathrm{dw}$ soil h${ }^{-1}$ (Fig. 1B). The potential $\mathrm{N}_{2} \mathrm{O}$ emission in paddy soil was the highest with CT treatment and the lowest with RTO treatment (8.1 and $4.6 \mathrm{ng} \mathrm{N}_{2} \mathrm{O}-\mathrm{N} \mathrm{g}^{-1}$ dw soil h ${ }^{-1}$, respectively). Compared with RTO treatment, the potential $\mathrm{N}_{2} \mathrm{O}$ emission in paddy soil with CT, RT and NT treatments was significantly increased $(p<0.05)$.

\section{Abundance of Denitrifiers Harboring nirS, nirK and nos Z}

These results indicated that abundance of nirK gene with CT, RT, NT and RTO treatments were ranged from 1.74 to 2.88 copies $\times 10^{9} \mathrm{~g}^{-1} \mathrm{dw}$ soil in paddy soil. Compared with NT and RTO treatments, the abundances of nirK gene with CT and RT treatments were significantly increased $(p<0.05)$ (Fig. 2A). Moreover, the abundances of nirS gene with CT, RT, NT, and RTO treatments were ranged from 0.41 to 0.85 copies $\times 10^{9} \mathrm{~g}^{-1} \mathrm{dw}$ soil in paddy soil, while the abundances of nirS gene with CT, RT and NT treatments were significantly higher $(p<0.05)$ than that of RTO treatment in paddy soil (Fig. 2B). These results indicated also that abundances of nosZ gene with CT, RT, NT and RTO treatments were ranged from 2.62 to 4.65 copies $\times 10^{8} \mathrm{~g}^{-1} \mathrm{dw}$ soil in paddy soil. Compared with RTO treatment, the abundances of nos Z gene with CT, RT and NT treatments were significantly increased (Fig. 2C).

A

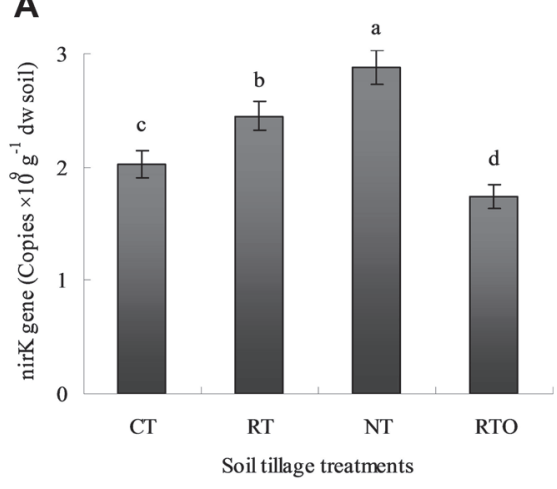

\section{B}

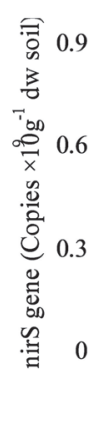

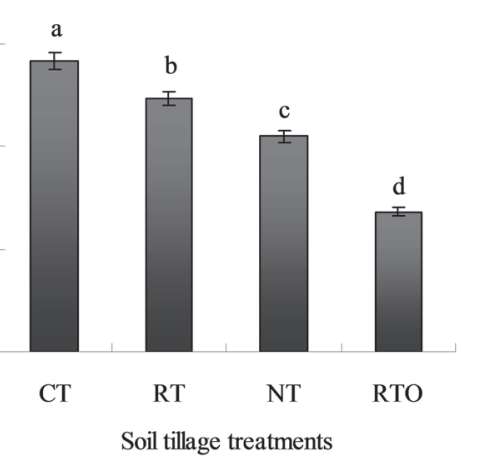

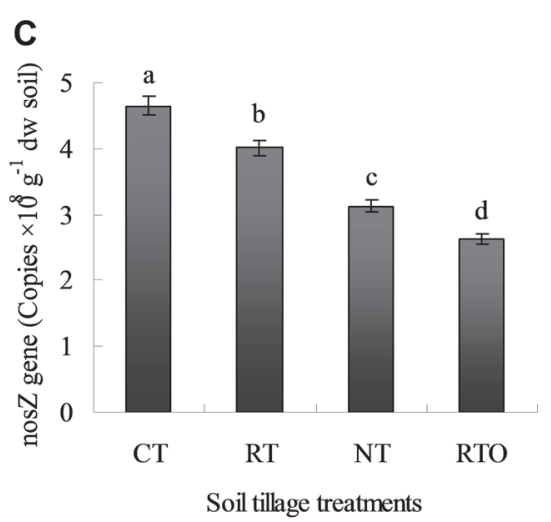

Fig. 2. Abundance of nirK, nirS and nosZ genes in paddy soil under different tillage treatments. (A) Abundance of nirK gene; (B) abundance of nirS gene; (C) abundance of nosZ gene. 
Table 2. Pearson's correlations ( $r$ ) between abundance of denitrification marker genes (nirK, nirS, and nosZ) and soil characteristics $(n=6)$.

\begin{tabular}{lccc}
\hline Items & qnirK & qnirS & qnosZ \\
\hline $\mathrm{pH}$ & $-0.83^{* *}$ & -0.35 & -0.41 \\
$\mathrm{TN}$ & $0.54^{*}$ & -0.17 & 0.45 \\
$\mathrm{SOC}$ & $0.53^{*}$ & -0.14 & 0.48 \\
$\mathrm{NH}_{4}{ }^{+}-\mathrm{N}$ & $0.65^{*}$ & 0.10 & $0.62^{*}$ \\
$\mathrm{NO}_{3}{ }^{-} \mathrm{N}$ & -0.22 & 0.24 & -0.30 \\
\hline
\end{tabular}

${ }^{\star}$ Significantly different at $p<0.05$. ${ }^{*}$ Significantly different at $p<0.01$.

The correlation between the abundance of denitrification marker genes (nirK, nirS, and nosZ) and soil characteristics were shown in Table 2 . There was a significantly positive correlation $(p<0.05)$ between abundance of nos $\mathrm{Z}$ gene and soil $\mathrm{NH}_{4}{ }^{+}-\mathrm{N}$ content $(r=0.62)$. There was a significantly positive correlation $(p<0.05)$ between abundance of nirK gene and soil TN content $(r=0.54)$, SOC content $(r=0.53)$, and NH4+-N content $(r=0.65)$.

However, there was no significantly $(p>0.05)$ correlation between abundance of nirS gene and soil characteristics. Meanwhile, there was a negatively correlation $(p<0.05)$ between abundance of nirK gene and soil $\mathrm{pH}(p<0.01 ; r=-0.83)$.

\section{Community Composition of Denitrifiers Harboring nirK, nirS, and nosZ}

Shannon diversity index of nirK, nirS and nosZ. These results indicated that Shannon diversity index of nirK in paddy soil with NT treatment were significantly higher $(p<0.05)$ than that of RTO treatment. The Shannon diversity index of nirK in paddy soil was significantly increased $(p<0.05)$ with CT, RT and NT treatments (Fig. 3A). The Shannon diversity index of nirS in paddy soil with RTO treatment was significantly lower $(p<0.05)$ than that of CT and RT treatments (Fig. 3B), indicating that this diversity index in paddy soil was decreased under crop residue removed condition. Also, the Shannon diversity index of nos $Z$ in paddy soil with CT treatment were significantly higher $(p<0.05)$ than that of RTO treatment (Fig. 3C), indicating that this diversity index in paddy soil was enhanced under combined application of tillage with crop residue condition.

PCoA of nirK, nirS, and nosZ. In the present study, the PCoA analysis indicated that the changes of the first principal coordinates (PCoA1) of nirK, nirS, and nosZ were explained as $43.15 \%, 46.37 \%$, and $47.18 \%$, respectively, demonstrating that different tillage treatments were the most important factor affecting the community of denitrifying bacteria in paddy soil (Fig. 4). Meanwhile, the change of second principal coordinates (PCoA2) of nirK, nirS, and nosZ were explained as $20.58 \%, 22.63 \%$, and $25.12 \%$, respectively, indicating that different crop residue returning management was the second most important factor affecting the community of denitrifying bacteria in paddy soil (Fig. 4).

Taxonomic distribution of nirK, nirS, and nosZ. These results indicated that nirK-denitrifying bacteria at the genus level in paddy soil were mainly included Alphaproteobacteria, Gammaproteobacteria, Deltaproteobacteria and Betaproteobacteria. The relative abundance of Betaproteobacteria were occupied most of the composition in paddy soil with CT, RT, NT, and RTO treatments, and the relative abundance of Betaproteobacteria in paddy soil with CT, RT, and NT treatments was higher $(p<0.05)$ than that of RTO treatment. However, the unclassified bacteria with RTO treatment were higher $(p<0.05)$ than that of CT, RT and NT treatments (Fig. 5A).

The nirS-denitrifying bacteria at the genus level in paddy soil were mainly included Deltaproteobacteria with CT, RT, NT, and RTO treatments. Compared with RTO treatment, the relative abundance of Gammaproteobacteria and Betaproteobacteria in paddy soil with CT, RT, and NT treatments were significantly increased $(p<0.05)$. However, the relative abundance of Planctomycetes in paddy soil with RTO treatment was significantly higher $(p<0.05)$ than that of CT, RT, and NT treatments (Fig. 5B).

The nosZ-denitrifying bacteria at the genus level in paddy soil were mainly included Nitrospirae with CT, RT, NT, and RTO treatments. Compared with RTO treatment, the relative abundances of Chloroflexi and Betaproteobacteria in paddy soil with CT, RT, and NT treatments were significantly increased $(p<0.05)$. However,

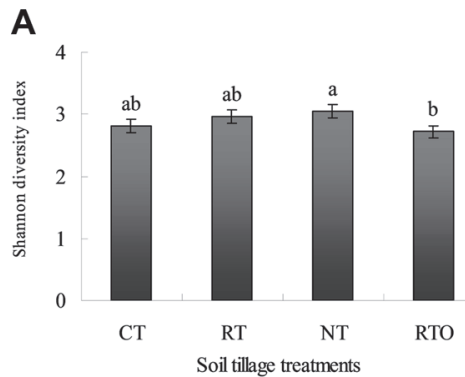

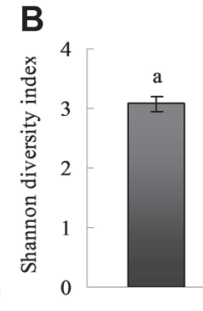

CT

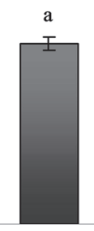

RT Soil tillage treatmen

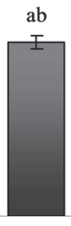

NT

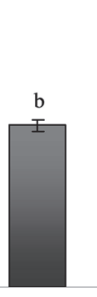

RTO

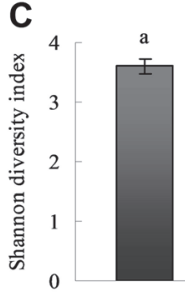

CT

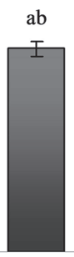

RT Soil tillage treatments

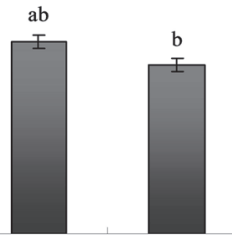

RTO

Fig. 3. Shannon diversity index of nirK, nirS, and nosZ library in paddy soil under different tillage treatments. (A) Shannon diversity index of nirK gene; (B) Shannon diversity index of nirS gene; (C) Shannon diversity index of nos Z gene. 

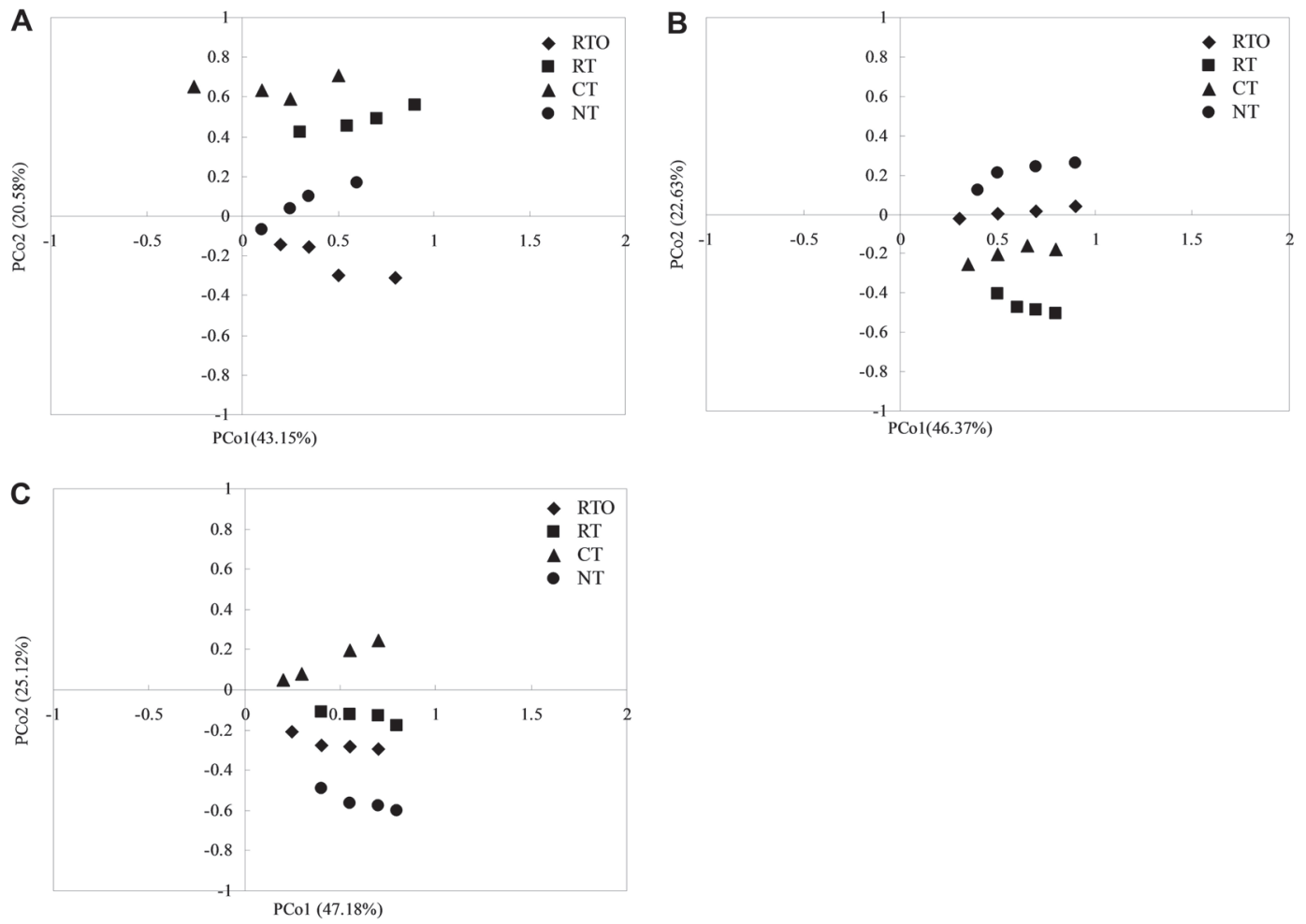

Fig. 4. Principal coordinate analysis (PCoA) of nirK, nirS, and nosZ library in paddy soil under different tillage treatments. (A) PCoA of nirK gene; (B) PCoA of nirs gene; (C) PCoA of nos Z gene.
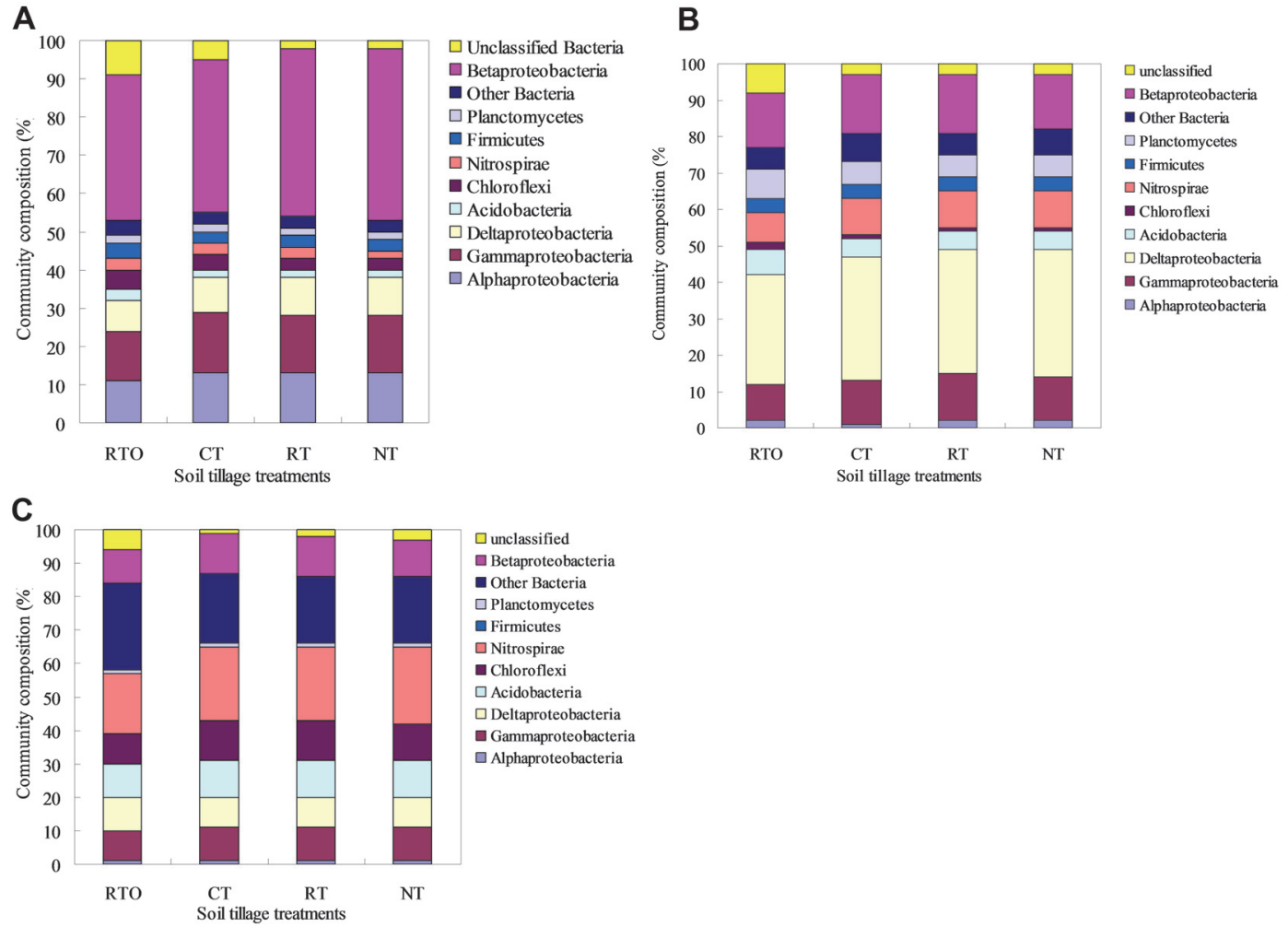

Fig. 5. Relative abundance of the nirK-, nirS-, and nosZ-type denitrifying bacteria at the genus level in paddy soil under different tillage treatments. (A) Relative abundance of nirK-denitrifying bacteria; (B) relative abundance of nirS-denitrifying bacteria; (C) relative abundance of nosZ-denitrifying bacteria. 
the relative abundance of the other bacteria and unclassified bacteria in paddy soil with RTO treatment were significantly higher $(p<0.05)$ than that of CT, RT, and NT treatments (Fig. 5C).

\section{Discussion}

In the previous study, it was found that community composition and diversity of soil denitrifying bacteria were changed by different tillage treatments in which soil $\mathrm{pH}$ was played an important role in regulating the denitrifying microbial community and diversity in arable soil [11]. In this study, the results showed that soil pH with RTO treatment was lower, but there was no apparent affects on $\mathrm{N}$ cycle soil denitrifiers communities (nirK, nirS, and nosZ-type). Soil $\mathrm{pH}$ was the main driving factors of $\mathrm{N}$-functional microbial community and diversity in soil [25], and this study revealed that there was obvious effect on soil pH between CT, RT, and NT treatments (Table 1). Compared with RTO treatment, soil $\mathrm{NO}_{3}{ }^{-} \mathrm{N}$ content and soil PDR were increased with NT treatment, and the soil denitrifying microbial community and diversity were obviously affected with NT treatment. Meanwhile, the soil available ammonium, inorganic N, organic N, SOC contents, and soil denitrification activities were obviously affected with CT and RT treatment. Therefore, the combined application of tillage with crop residue management can manipulate the $\mathrm{N}$-functional microbial population and then affect the properties of double-cropping paddy soil.

In the present study, there was significantly difference in soil PDR among CT, RT, and NT treatments, and the numbers of nirS, nirK, and nosZ genes copies with CT, RT, and NT treatments were increased compared to RTO treatment, that is, the number of soil denitrification gene copies had a significantly overall affected under combined application of tillage with crop residue condition. These findings were similar with those of Chen et al. [3] in which the numbers of nirS, nirK, and nosZ genes copies in paddy soil with crop residue management were increased compared to without fertilizer input management base on the long-term field experiment condition. It was benefitial for soil denitrifiers multiplcation with CT and RT treatments, which was related to higher bioavailability of $\mathrm{C}$ under these soil environment condition [26]. On the other hand, there had higher soil $\mathrm{NH}_{4}^{+}-\mathrm{N}$ and SOC contents were higher under CT and RT conditions (Table 1), which were positively correlated with the number of nos Z and nirK genes copies in paddy soil (Table 2). These findngs were similar to those of Kandeler et al. [27] which showed that, SOC content was positively correlated with the number of soil denitrification gene copies (narG, nirK, and nosZ). In this study, the results indicated that communities of nirK and nirS were responded differently to tillage treatments, although both the numbers of nos $Z$ and nirK genes copies with CT, RT and NT treatments were increased compared with RTO treatment. The numbers of nirS gene copies with CT and RT treatments were higher than that of NT treatment, indicated that soil denitrifiers of nirS growth and development maybe sensitive to combined application of tillage with crop residue management compared with no-tillage and crop residue management. In contrast, the abundance of soil denitrifiers nirK gene copies with CT and RT treatments were decreased compared with NT treatment. The main reason for this phenomenon in this study was maybe that the number of soil denitrifiers nirS gene copies depended on tillage management, crop residue and root exudates, whereas the soil denitrifiers nirK gene copies may have relied on tillage management, crop residue and root exudates to a lesser degree.

In the present study, we found that the abundances of soil denitrifiers nirK gene copies were more closely related to soil physicochemical characteristics than that of the other soil denitrifiers genes (nos $Z$ and nirS). And the abundance of soil denitrifiers nirK gene copies were more than three times higher than that abundance of soil denitrifiers nirS gene copies with CT, RT, NT, and RTO treatments (Fig. 2). Meanwhile, this result indicated that one copy of nirS were found in bacterial genomes, whereas three copies of nirK were found in some species [28]. And the abundance of denitrifiers nirK were higher than that of abundance of denitrifiers nirS in paddy soil for that all nitrite-reducing bacteria have either nirK or nirS. These founds were similar to Yoshida et al. [13] result, which also had found abundance of soil denitrifiers nirK were higher than that of abundance of soil denitrifiers nirS. However, Kandeler et al. [27] study showed a reversed result that abundant of denitrifiers nirS were higher than that of abundant of denitrifiers nirK in glacier soil. In the present study, there had higher abundant of denitrifiers nirK in paddy soil, but there is still little information about this phenomenon could be related to different fertilizer regime, irrigation pattern and other paddy field management.

In the previous studies, these results demonstrated that community composition and diversity of denitrifier were playing a vital role in regulating denitrification rate and $\mathrm{N}_{2} \mathrm{O}$ emission in soil $[5,6]$. Therefore, the closely related to denitrifying genes (nirK, nirS, and nosZ) in the soil denitrifying microbial community were studied [13]. In the present study, the results showed that soil PDR were significantly changed under combined application of tillage with crop residue condition compared with no-tillage with crop residue management, although the nirS community were moderate changed with NT treatment. Wang et al. [10] also found that abundance of soil denitrifiers nirK and nirS genes with no-tillage treatment were lower than that of ploughing tillage treatment, while abundance of soil denitrifiers nosZ gene with no-tillage treatment were higher than that of ploughing tillage treatment, which was consistent with our finding in this study. Meanwhile, our results showed that abundance of denitrifiers nirK gene were significantly higher than that of abundance of denitrifiers nirS gene in paddy soil (Fig. 2), which was similar to previous results $[3,13]$, the reason maybe that attribute to the same type of soil and climate in this experimental region. In the present study, it was significantly to attention that number of soil denitrifiers genes copies (nirK, nirS, and nosZ) were changed under different tillage management condition [11]. For example, there had multiple number of soil denitrifiers nirK gene copies compared with number of soil denitrifiers nirS gene copies (sometimes were presented in multiple copies) [28]. Therefore, our results provide guidance for researchers to separate abundance of the special soil denitrifiers gene-carrying microorganisms, this 
maybe explain the difference between number of soil denitrifiers gene copies and soil potential denitrification rates.

In the present study, a remarkable discovery was that community composition and diversity of soil denitrifiers (nirK, nirS, and nosZ) were responded difference to the tillage treatments. The community composition of soil denitrifiers nirK and nirS were clearly changed between tillage treatments, and the community composition and diversity of nos $Z$ were also significantly changed. That is, this results indicated that the community composition of denitrifying bacteria in double-cropping paddy soil were nirK and nirS under different tillage management condition. As a result, the higher community composition and diversity of nirK, nirS, and nos Z with tillage and crop residue management consistent with our hypothesis that structure of soil denitrifier communities were changed under combined application of tillage with crop residue condition. Some studies had conducted to compare with community composition and diversity of nirK, nirS, and nos $Z$ with different tillage management in agricultural system. Wang et al. [10] indicated that denitrifying community composition of nirK and nirS were influenced by long-term plough tillage management. However, there is still need to further study on the change of nirS and nos $Z$ community responding to environmental factor. Although the denitrifying community composition of nirS and nos $Z$ in soil were needed to further magnify for that primer specificity problem [29]. In the present study, these primers used for qPCR were same as the conventional PCR were conducted following previous study [20]. Our results suggested that community composition of denitrifiers nirK and nirS in paddy soil were more sensitive to tillage treatments than that of community composition of soil denitrifiers nos $Z$, which was consistent with a previous research [30], who found that napA and narG genes had different responses to tillage management. Therefore, these results indicated that community composition and diversity related to soil denitrification were respond difference to tillage and crop residue management changes.

In the present study, we demonstrated that soil bacterial community composition and diversity of denitrifiers were significantly changed under combined application of tillage with crop residue condition. For instance, the principal coordinate analysis revealed that soil bacterial community composition of denitrifiers were also changed under different tillage treatments condition (Fig. 4). These findings are consistent with previous research showing that soil ammonia-oxidizing bacterial communities were changed by application of different tillage treatment at the same region [12], Our findings demonstrated that tillage management was the dominant factor in regulating soil bacterial community composition of denitrifiers. Other results have also found that community composition of soil denitrifiers responds differently according to tillage management [11], and these differences have been ascribed to change in soil pH, SOC content or other soil properties. Meanwhile, in the present study, the Pearson correlation coefficients analysis indicated that there had significantly correlation between bacterial community composition of soil denitrifiers and soil properties (Table 2), implying that bacterial community composition of soil denitrifiers in this region was obviously affected by the change of soil parameters, which also indicated that different tillage practices were also another significant factor changing the soil denitrifying bacteria community.

In this study, we showed that community composition of soil denitrifiers nirK, nirS, and nosZ were significantly changed by combined application of tillage with crop residue management, a significantly increased in the diversity was also observed (Figs. 3-5), and denitrifying bacteria community composition were dominated by Gammaproteobacteria, Deltaproteobacteria and Betaproteobacteria. The predominance of nirK, nirS, and nosZ diverse denitrifying bacteria was also consistent with the results of a previous analysis of paddy soil [30]. In the present study, the dominant relative abundance of nirK and nos $Z$ obtained were related to Gammaproteobacteria. Contrary, Chen et al. [3] result indicated that the dominant relative abundance of nos $Z$ obtained were related to Alphaproteobacteria and Betaproteobacteria in paddy soil under long-term fertilizer condition. However, Masuda et al. [31] result found that most nirS OTUs were attached to the Betaproteobacteria in paddy soil. It was possible that nirS-carrying Betaproteobacteria were partial denitrifying bacterial, and lacking enzymes downstream of $\mathrm{NiR}$, only two-thirds of NiR or nitric oxide reductase harbor $\mathrm{N}_{2} \mathrm{OR}$ [2]. Alternatively, we used primers that are highly specific for Deltaproteobacteria nos $Z$ used primers were investigated in the present study. Therefore, this study demonstrated that soil microbial communities driving nitrite or reducing of nitric oxide were difference from each other, and the major drivers of nitrite or nitric oxide reduction were Deltaproteobacteria, Gammaproteobacteria and Betaproteobacteria, respectively. In the previous study, the result had proved that soil denitrifiers were related to environmental factor change and the different denitrification genotypes were also difference in response to the environmental factors [3]. Soil microbial communities were altered by combined application of tillage with crop residue management for that soil properties were also changed [32]. In the present study, the Pearson's correlations results demonstrated that community composition of soil denitrifiers was significantly affected by soil $\mathrm{pH}, \mathrm{NH}_{4}{ }^{+}-\mathrm{N}$, total $\mathrm{N}$ and $\mathrm{SOC}$ contents (Table 2). Soil $\mathrm{NH}_{4}{ }^{+}-\mathrm{N}$ content was the vital factor influencing on the community composition of denitrifiers and for that it was also the main substrate for denitrification. Previous study, it had proved that community composition and diversity of soil denitrifiers in selecting special functional groups were also mainly affected by soil pH [3]. Šimek and Cooper (2002) [33] result found that available organic carbon was utilized by soil microorganisms mainly influenced by soil $\mathrm{pH}$, thus community structure of soil denitrifiers was also altered. Therefore, the effects of combined application of tillage with crop residue management on change in chemical characteristics (Table 1) and microbial community composition in paddy soil (Figs. 3-5) is still needs to further study. These special functional soil microbial community structures and abundances played vital roles in the cycling process of soil nitrogen. However, the relationship between tillage, crop residue management and soil nutrient cycling process were remained unclear, and the major factors affecting the structure and abundance of nirK, nirS, and nos $Z$ were also needed further study to understanding the role of nitrite reducers in soil systems. 


\section{Acknowledgments}

This study was supported by the National Natural Science Foundation of China (31872851, 41807008), and the Innovative Research Groups of the Natural Science Foundation of Hunan Province (2019JJ10003).

\section{Conflict of Interest}

The authors have no financial conflicts of interest to declare.

\section{References}

1. Henry S, Baudoin E, Lopez-Gutierrez JC, Martin-Laurent F, Baumann A, Philippot L. 2004. Quantification of denitrifying bacteria in soils by nirK gene targeted real-time PCR. J. Microbiol. Methods 59: 327-335.

2. Zumft W. 1997. Cell biology and molecular basis of denitrification. Microbiol. Mol. Biol. Rev. 61: 533-616.

3. Chen Z, Luo X, Hu R, Wu M,Wu J, Wei W. 2010. Impact of long-term fertilization on the composition of denitrifier communities based on nitrite reductase analyses in a paddy soil. Microb. Ecol. 60: 850-861.

4. Braker G, Zhou J, Wu L, Devol AH, Tiedje JM. 2000. Nitrite reductase genes (nirK and nirS) as functional markers to investigate diversity of denitrifying bacteria in Pacific northwest marine sediment communities. Appl. Environ. Microbiol. 66: $2096-2104$.

5. Li S, Song L, Jin Y, Liu S, Shen Q, Zou JW. 2016. Linking $\mathrm{N}_{2} \mathrm{O}$ emission from biochar-amended composting process to the abundance of denitrify (nirK and nosZ) bacteria community. AMB Exp. 6: 37.

6. Yang L, Zhang X, Ju X. 2017. Linkage between $\mathrm{N}_{2} \mathrm{O}$ emission and functional gene abundance in an intensively managed calcareous fluvo-aquic soil. Sci. Rep. 7: 43283.

7. Schulz S, Kolbl A, Ebli M, Buegger F, Schloter M, Fiedler S. 2017. Field-scale pattern of denitrifying microorganisms and $\mathrm{N}_{2} \mathrm{O}$ emission rates indicate a high potential for complete denitrification in an agriculturally used organic soil. Microb. Ecol. 74: 765-770.

8. Elder JW, Lal R. 2008. Tillage effects on gaseous emissions from an intensively farmed organic soil in North Central Ohio. Soil Tillage Res. 98: 45-55.

9. Rochette P. 2008. No-till only increases $\mathrm{N}_{2} \mathrm{O}$ emissions in poor lyaerated soils. Soil Tillage Res. 101: 97-100.

10. Wang WY, Yang M, Shen PF, Zhang RY, Qin XL, Han J, et al. 2019. Conservation tillage reduces nitrous oxide emissions by regulating functional genes for ammonia oxidation and denitrification in a winter wheat ecosystem. Soil Tillage Res. 194: 104347.

11. Tatti E, Goyer C, Burton DL, Wertz S, Zebarth BJ, Chantigny M, et al. 2015. Tillage management and seasonal effects on denitrifier community abundance, gene expression and structure over winter. Microb. Ecol. 70: 795-808.

12. Yu ZH, Liu JJ, Li Y S, Jin J, Liu XB, Wang GH. 2018. Impact of land use, fertilization and seasonal variation on the abundance and diversity of nirS-type denitrifying bacterial communities in a Mollisol in Northeast China. Eur. J. Soil Biol. 85: 4-11.

13. Yoshida M, Ishii S, Otsuka S, Senoo, K. 2009. Temporal shifts in diversity and quantity of nirS and nirK in a rice paddy field soil. Soil Biol. Biochem. 41: 2044-2051.

14. Yin C, Fan F, Song A, Cui P, Li T, Liang Y. 2015. Denitrification potential under different fertilization regimes is closely coupled with changes in the denitrifying community in a black soil. Appl. Microbiol. Biotechnol. 99: 5719-5729.

15. Yang XY, Ren WD, Sun BH, Zhang SL. 2012. Effects of contrasting soil management regimes on total and labile soil organic carbon fractions in a loess soil in China. Geoderma 177-178: 49-56.

16. Tang HM, Xiao XP, Li C, Tang WG, Cheng KK, Pan XC, et al. 2019. Effects of different soil tillage systems on soil carbon management index under double-cropping rice field in southern China. Agron. J. 111: 440-446.

17. Bao SD. 2000. Soil and Agricultural Chemistry Analysis. Pp. 49-56. China Agriculture Press, Beijing.

18. Molstad L, Dorsch P, Bakken LR. 2007. Robotized incubation system for monitoring gases $\left(\mathrm{O}_{2}, \mathrm{NO}, \mathrm{N}_{2} \mathrm{O}\right.$ and $\left.\mathrm{N}_{2}\right)$ in denitrifying cultures. J. Microbiol. Methdos 71:202-211.

19. Drury CF, Myrold DD, Beauchamp EG, Reynolds WD. 2007. Denitrification techniques for soils. In Carter MR, Gregorich ED (eds.), pp. 471-493. Soil sampling and methods of analysis, 2nd ed. CRC Press, Boca Raton.

20. Throbäck IN, Enwall K, Jarvis Å, Hallin S. 2004. Reassessing PCR primers targeting nirS, nirK and nosZ genes for community surveys of denitrifying bacteria with DGGE. FEMS Microbiol. Ecol. 49: 401-417.

21. Long X, Chen C, Xu Z, Linder S, He JZ. 2012. Abundance and community structure of ammonia oxidizing bacteria and archaea in a Sweden boreal forest soil under 19-year fertilization and 12-year warming. J. Soils Sediments 12: 1124-1133.

22. Jung J, Yeom J, Kim J, Han J, Lim HS, Park H, et al. 2011. Change in gene abundance in the nitrogen biogeochemical cycle with temperature and nitrogen addition in Antarctic soils. Res. Microbiol, 162: 1018-1026.

23. Zeng J, Liu XJ, Song L, Lin XG, Zhang HY, Shen CC, et al. 2016. Nitrogen fertilization directly affects soil bacterial diversity and indirectly affects bacterial community composition. Soil Biol. Biochem. 92: 41-49.

24. SAS Institute Inc. 2013. SAS 9.4 in-database products: user's guide. 3rd ed. SAS Institute Inc.; Cary, NC.

25. Enwall K, Philippot L, Hallin S. 2005. Activity and composition of the denitrifying bacterial community respond differently to longterm fertilization. Appl. Environ. Microbiol. 71: 8335-8343.

26. Cao YP, Green PG, Holden PA. 2008. Microbial community composition and denitrifying enzyme activities in salt marsh sediments. Appl. Environ. Microbiol. 74: 7585-7595.

27. Kandeler E, Deiglmayr K, Tscherko D, Bru D, Philippot L. 2006. Abundance of narG, nirS, nirK, and nosZ genes of denitrifying bacteria during primary successions of a glacier foreland. Appl. Environ. Microbiol. 72: 5957-5962.

28. Jones CM, Stres B, Rosenquist M, Hallin S. 2008. Phylogenetic analysis of nitrite, nitric oxide, and nitrous oxide respiratory enzymes reveal a complex evolutionary history for denitrification. Mol. Biol. Evol. 25: 1955-1966.

29. Avrahami S, Conrad R, Braker G. 2002. Effect of soil ammonium concentration on $\mathrm{N}_{2} \mathrm{O}$ release and on the community structure of ammonia oxidizers and denitrifiers. Appl. Environ. Microbiol. 68: 5685-5692.

30. Chèneby D, Brauman A, Rabary B, Philippot L. 2009. Differential responses of nitrate reducer community size, structure, and activity to tillage systems. Appl. Environ. Microbiol. 75: 3180-3186.

31. Masuda Y, Matsumoto T, Isobe K, Senoo K. 2019. Denitrification in paddy soil as a cooperative process of different nitrogen oxide reducers, revealed by metatranscriptomic analysis of denitrification-induced soil microcosm. Soil Sci. Plant Nutr. 65: $342-345$.

32. Lehmann J, Rillig MC, Thies J, Masiello CA, HockadayWC, Crowley D. 2011. Biochar effects on soil biota-a review. Soil Biol. Biochem 43: 1812-1836.

33. ŠImek M, Cooper J. 2002. The influence of soil $\mathrm{pH}$ on denitrification: progress towards the understanding of this interaction over the last 50 years. Eur. J. Soil Biol. 53: 345-354. 